\title{
Voltage Profile Improvement of Distribution System via Integration of Distributed Generation Resources
}

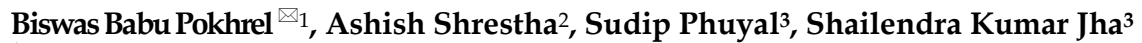 \\ ${ }^{1}$ School of Engineering, Mid-Western University, Surkhet 21700, Nepal \\ ${ }^{2}$ Department of Electrical Engineering, Information Technology and Cybernetics, University of South-Eastern \\ Norway, Porsgrunn N-3918, Norway \\ 3Department of Electrical and Electronics Engineering, Kathmandu University, Dhulikhel 45200, Nepal \\ ${ }^{\circledR}$ Corresponding Author: pokharelbabubiswas@gmail.com | Phone: +977-9849002378
}

Received : January 16, $2021 \quad$ Revision : February 11, $2021 \quad$ Accepted : March 5, 2021

\begin{abstract}
This study attempts to identify the causes and possible solutions for voltage profile issues in the lower land of Nepal, and is specifically focused on Laukahi feeder, a radial distribution system with an approximate length of $65 \mathrm{~km}$ and distributed at $11 \mathrm{KV}$ system voltage. Currently, the end-users feeding through this feeder is getting drop voltage along with frequent interruptions in the power supply. In this study, a forward/ backward sweep algorithm is used to analyze the load flow of the distribution system, whereas the ant colony optimization (ACO) technique is used to identify the best location for the Distributed Generator (DG) penetrations. After completion of this study, it is found that, the branch loss of the feeder can be reduced up to $87.22 \%$, and the voltage profile can be improved from $0.828 \mathrm{pu}$ to 0.982 pu by integrating some form of DGs.
\end{abstract}

Keywords : Ant Colony Optimization; Distributed Generation;Power System; Radial Distribution System

\section{Introduction}

Nepal is a country dominated by hydropower; yet power extractions from other renewable sources such as wind, solar and biomass are being emerged nowadays. Even though the neighbouring countries are now able to generate hundreds of Megawatts of power from Solar PV, electricity from hydropower is still the cheapest in long run for the country due tothe abundance of natural resources(Peng et al., 2014; Sahoo, 2016). In generating stations, power generation has constraint power output; however, the demand is varying with various parameters such as time, income, weather, season etc. (Ashish Shrestha et al., 2019). Hence, the electricity utility's responsibility is to deliver electricity to the load centre as per demand without fluctuations in the rated standard parameters such as voltage, frequency etc. which is much challenging. With the introduction of low-cost electricity using renewable sources, limitations in placing multiple small and medium power generation sources are now been resolved and opportunity for distributed generation integration is emerging these days (Ashish Shrestha et al., 2019; A Shrestha et al., 2016). To overcome the gap between demand and generation, alternative energy sources at an alternative place (where needed) for generation is being quite popular (Ackermann et al., 2001; Sah et al., 2018) in recent days. DG has different identification with the need of researchers; nevertheless, one common understanding among them is power generation source having less than main (or grid) generation sources (power supply capability) and is mostly situated at the load centre is termed as DG, and it couldn't be alternative but supportive for the main generation (Pramish Shrestha et al., 2018).

The electrical distribution system mainly faces direct and indirect losses where direct loss is associated with the magnitude of flowing current such as dissipating heat due to I2R loss in the lines and indirect loss represents the losses due to intentional or unintentional human involvement (Civanlar et al., 1988; Ashish Shrestha, 2017; Verayiah, Mohamed et al., 2014). The distribution power line also has some power quality issues such as voltage drop, voltage sag, voltage fluctuation, voltage flicker, transient voltages etc. These are some common problems in the distribution systems globally, which are occurred due to the reasons such as loading pattern, length of the line, consumer behaviour in the feeder etc. (Sampath, 2015). The electrical distribution system has some unique characteristics than the transmission line such as radial meshed structure, multiphase and unbalanced operation, unbalanced distributed load, an extremely large number of branches and nodes, and a high R/X ratio (Ashish Shrestha et al., 2016). Generally, the R/X ratio of the distribution system is very high resulting in the high voltage drop and power loss in the system (Ashish Shrestha et al., 2018). Due to these characteristics, conventional Newton Raphson and Gauss-Seidel methods may provide inaccurate results and also may fail to converge (Ashish Shrestha et al., 2016; Teng, 2003). For that reason, various load flow equations applicable for radial distribution system were proposed (Prenc, Škrlec, \& Komen, 2013). Moreover, the forward/ backward sweep algorithm is quite popular among them due to its easiest modulation (Bompard et al., 2000). Typical DG problem is related to optimal size and locations of DG which is a combination of discrete and continuous function. For this reason, deterministic methods are unable to deal with the size and place simultaneously. This is the real challenge to all calculusbased optimization methods and opportunities for the heuristic and population-based methods such as particle swarm 
optimization (PSO), bacterial foraging algorithm (BFA), Genetic algorithm (GA), ACO etc. (Farhat, 2013; Ajay Singh et al., 2018). Correlating with animal behaviour, many researchers have developed a mathematical optimization model. Optimization is the process to get the maximum possible output with the least possible input or is defined as it is the act of obtaining the best results under the given circumstances. Moreover, the main goal of optimization is to minimize the effort required to get the maximized benefit (Pazhaniraja et al., 2017). For instance, inspired by the food foraging characteristics of ant, the ACO technique was developed. Furthermore, from the cuckoo's lay behaviour, cuckoo search algorithms are in place. Likewise, Whale optimization, PSO, GA, Firefly algorithm, Lion Optimization Algorithm (LOA) etc. have been using in power system planning (Balamurugan et al., 2018; Seidlová \& Poživil, 2005; Shekhawat et al., 2009; Yang, 2009; Yang \& Deb, 2009; Yazdani \& Jolai, 2016). Nikoukar and Gandomkar(Nikoukar \& Gandomkar, 2005), has compared the power loss in a distribution system using Genetic algorithm (GA), Genetic Algorithm and Tabu Search (GA-TS), and the ACO, from which it was concluded that ACO gives the best results compared to other algorithms.

In this study, the concept of DG integration on radial distribution system is analyzed to improve the voltage profile at the end-user level. This study first introduces the issues and challenges that occurred in the radial distribution system and the role of DG to incorporate them. Section 2 presents the details of the case study area, whose real data were taken to analyze the system performance. In section 3, applied methodologies and approaches are explained. Section 4 presents the research outcome and their discussion. Finally, in section 5, conclusions are drawn based on the conducted analysis.

\section{Current Scenario of the Case Study Area}

In this study, the case of Inaruwa Distribution and Consumer Service (DCS) is considered, which is located in Sunsari district of Nepal with $33 / 11 \mathrm{kV}$ substation, providing power to the consumers through 5 different feeders at $11 \mathrm{kV}$. During the problem assessment in this substation, the extremely poor voltage had been identified facing by the consumers. Normal activities have been affected due to the low voltage (around $90-115 \mathrm{~V}$ in $230 \mathrm{~V}$ rated voltage level for domestic household consumers). Considering all connected feeders in this substation, the Laukahi feeder is the longest one with approximate $65 \mathrm{~km}$ in length. Figure 1 shows the layout of the DCS, and the detailed single line diagram of the Laukahi feeder is shown in Figure 2. It has a total 76 number of buses, from which several consumers are getting supply through 11/0.4kV transformer. Dog conductor $(R=0.2712 \square / \mathrm{km}$ and $X=0.2464 \square / \mathrm{km})$ is used to transmit the power for this feeder from the substation. Many electric agro-processing mills, timber and furniture mills, small irrigation projects along a large number of domestic households are in dependence on this feeder. The maximum loading of this feeder was calculated to be $3,536 \mathrm{~kW}$ and 2,652 kVAR by direct measurement, considering the line being operated at full load.

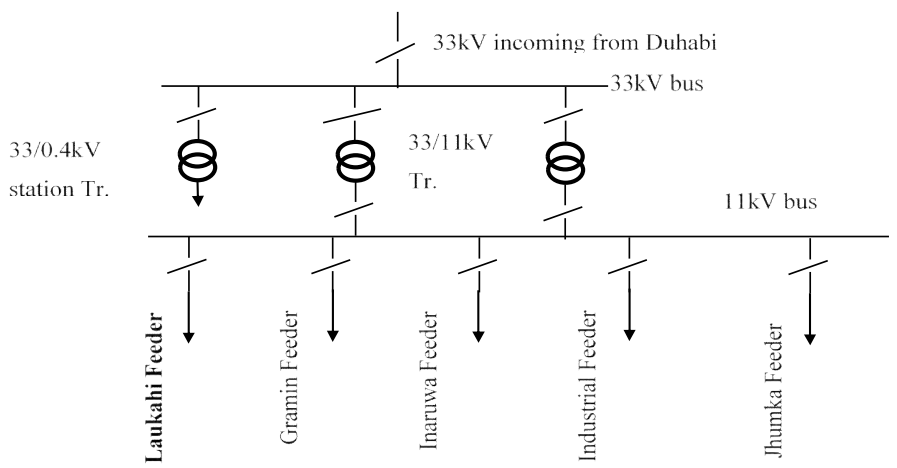

Figure 1: Layout of Inaruwa DCS

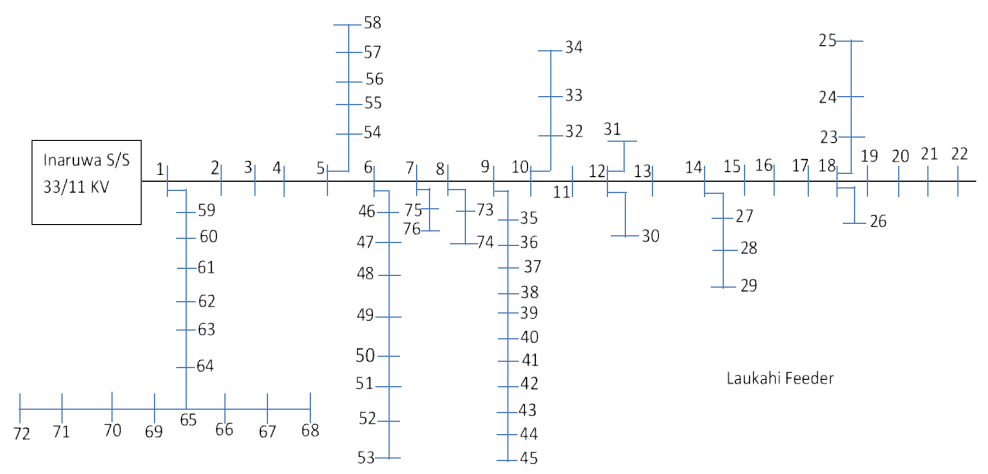

Figure 2: SLD of Laukahi Feeder

Although individual feeder has different loading pattern and length, low voltage problem is found to be common for all. Due to the low voltage issue, some of the small and cottage industry consumers are using diesel generator and some are curtailing their production, resulting both are hindering productivity and profit. Hence, it is very important to analyze the system's performance for this case study area. 


\section{Materials \&Methods}

In this study, the substation is considered as bus 1 (reference bus) having voltage $1 \measuredangle 0$ throughout the calculation. In the distribution line from a point where each $11 / 0.4 \mathrm{kV}$ transformer gets supply through tapping in $11 \mathrm{kV}$ line is considered as a bus and line connecting two such buses is considered as a branch. Each branch has finite resistance and reactance $(\mathrm{R} \& \mathrm{X})$ values. Further, the capacity of the transformer (kVA rating) is denoted by apparent power $\mathrm{S}$. The adopted network model is shown in Figure 3. In a large distribution network, it is challenging to identify the start node and end node of the branch. During modelling, individual bus, branch and transformer loading should be numbered accordingly, otherwise, the result will mislead the general assumption. Hence, initially, the data of the network is collected and tabulated as shown in Table 1. For proper identification of a bus, branch and respective load, a BraBus matrix is created with a unique size: [Branch number $x$ Bus number]. In this matrix, starting bus and the end bus is denoted by ' 1 ' \& ' -1 ' respectively, and the rest of the elements are considered to be zero. For the considered network as shown in Figure 3, the associated BraBus matrix is determined and shown in Table 2. Here, each column number depicts the bus number having bus voltage and loading of the network, and each column having multiple ' 1 ' values reflects the branching bus. In Table 2, a second column containing two ' 1 ' denotes the branching bus in the network. Every row will have a single ' 1 ' and ' -1 ', i.e. branch and the corresponding row number is known as branch number. Each branch is holding current, impedance, and branch loss data. (Bompard et al., 2000)

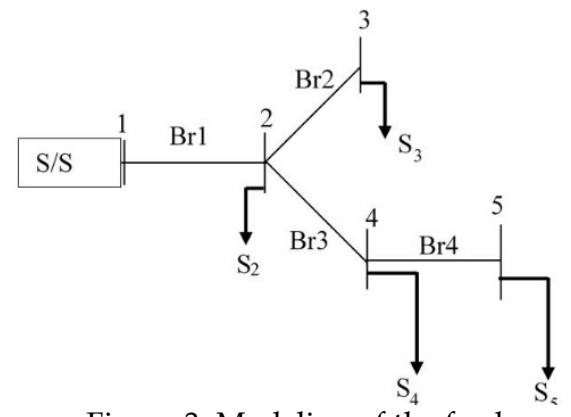

Figure 3: Modeling of the feeder

Table 1: Description table of the network

\begin{tabular}{ccccccc}
\hline S.N. & From Bus & To Bus & $\mathbf{R}$ & $\mathbf{X}$ & $\mathbf{k W}$ & $\mathbf{k V A R}$ \\
\hline 1 & 1 & 2 & R1 & X1 & P1 & Q1 \\
2 & 2 & 3 & R2 & X2 & P2 & Q2 \\
3 & 2 & 4 & R3 & X3 & P3 & Q3 \\
4 & 4 & 5 & R4 & X4 & P4 & Q4 \\
\hline
\end{tabular}

Table 2: BraBus matrix of the network

\begin{tabular}{cccccc}
\hline Branch & Bus 1 & Bus 2 & Bus 3 & Bus 4 & Bus 5 \\
\hline Branch 1 & 1 & -1 & 0 & 0 & 0 \\
Branch 2 & 0 & 1 & -1 & 0 & 0 \\
Branch 3 & 0 & 1 & 0 & -1 & 0 \\
Branch 4 & 0 & 0 & 0 & 1 & -1 \\
\hline
\end{tabular}

After developing the network and its parameters, a forward/ backward sweep algorithm is used to analyze the load flow in the network, and the ACO technique is used to choose the best location of DG penetration. Similarly, the capacitor bank is considered as a reactive power source and solar PV is considered as a DG source that provides the active power to the network. However, due to technical constraints, the size of DG is limited to $45 \%$ of the total connected active load (Kadir et al., 2014). Further, the maximum size of the capacitor bank is estimated to serve all the connected reactive loads. The detail approaches of the adopted algorithms are described as below:

\section{A. Backward Sweep Algorithm}

In a backward sweep algorithm, initially, branch currents $\left(\mathrm{Ibr}_{1}, \mathrm{Ibr}_{2}, \ldots \ldots . ., \mathrm{Ibr} \mathrm{r}_{\mathrm{N}}\right)$ should be calculated from the end bus, in which BraBus matrix plays a significant role. The current is calculated by using the equation $S=\mathrm{VI}^{*}$, which yields the current at each branch. Let say, we need to know the value of branch current of the network (Figure 3) at branch 4 , and is calculated by using Equations 1 and 2 . Where $V_{5} \mathrm{~m}$ is the initial bus voltage of bus number 5 .

$$
\begin{aligned}
I b r_{4} & =\left(\frac{S_{5}}{V_{5}{ }^{m}}\right)^{*} \\
I b r_{3} & =\left(\frac{S_{4}}{V_{4}{ }^{m}}\right)^{*}+I b r_{4}
\end{aligned}
$$

Likewise, the current is summed up from the end bus to starting bus as shown in Table III. In this way, the final current (or total current) of the network is calculated by using Equation 3.

$$
I b r_{\text {total }}=I b r_{1}+I b r_{2}+\cdots \ldots \ldots \ldots+I b r_{N}
$$


This algorithm simply follows Kirchhoff's current law to sum the total branch current. Once all the current is calculated, then the forward sweep approach is followed to estimate the bus voltage. For the forward sweep, all of the calculated branch current in the backward sweep is used.

\section{B. Forward Sweep Algorithm}

This algorithm is used to calculate the bus voltage with the help of branch current, calculated in backward sweep and branch impedance from the table formulated in data collection. The general assumption for this algorithm is, the voltage at starting bus (or slack bus or substation) is always $1 \Varangle 0$. The voltage at the bus connected with starting bus is calculated by using simply Kirchhoff's voltage law.

$$
V_{2}^{m+1}=V_{1}^{m}-I b r_{1} * Z_{1}
$$

In this way, the bus voltage calculation process will go up to the end bus, and the end bus voltage (say $V_{N}$ ) is calculated as [1],

$$
V_{N}^{m+1}=V_{N-1}^{m}-I b r_{k} * Z_{k}
$$

Where $I_{b r k}$ is end branch current, $Z_{k}$ is end branch impedance $\left(R_{k}+j X_{k}\right), V_{i}^{m}$ is initial bus voltage and $V_{N}{ }^{m+1}$ is the updated bus voltage of $\mathrm{N}^{\text {th }}$ bus. Let say, i represents any bus number of the system, after calculating the bus voltage $V_{i}{ }^{m+1}$, it was compared with the previous bus voltage $\mathrm{V}_{\mathrm{i}} \mathrm{m}$, if the difference is less than or equals to a predefined value (i.e. $\Delta \mathrm{V}<$ 0.00001 ), then the bus voltage $\mathrm{V}_{\mathrm{i}}^{\mathrm{m}+1}$ is stored. After receiving the value of bus voltage and branch current using the forward/ backward sweep algorithm, branch loss can be calculated in an active and reactive form as given by Equations 6 and 7.

$$
\begin{aligned}
k W_{b r 1} & =\left(I_{b r 1}\right)^{2} * R_{b r 1} \\
k W_{b r N} & =\left(I_{b r N}\right)^{2} * R_{b r N}
\end{aligned}
$$

$\mathrm{I}^{2} \mathrm{R}$ loss in each branch is denoted by $\mathrm{kW}_{\mathrm{bri}}$, as shown in Equation 6, i denotes the branch number, $\mathrm{I}_{\mathrm{br}}$ represents the

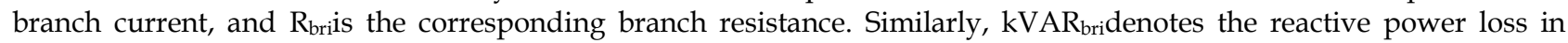
branch ' $i$ ' as in Equation 9. With the help of equation (1) to (9), all node voltages, branch current and branch loss can be estimated for a given network.

$$
\begin{aligned}
k V A R_{b r 1} & =\left(I_{b r 1}\right)^{2} * X_{b r 1} \\
k V A R_{b r N} & =\left(I_{b r N}\right)^{2} * X_{b r N}
\end{aligned}
$$

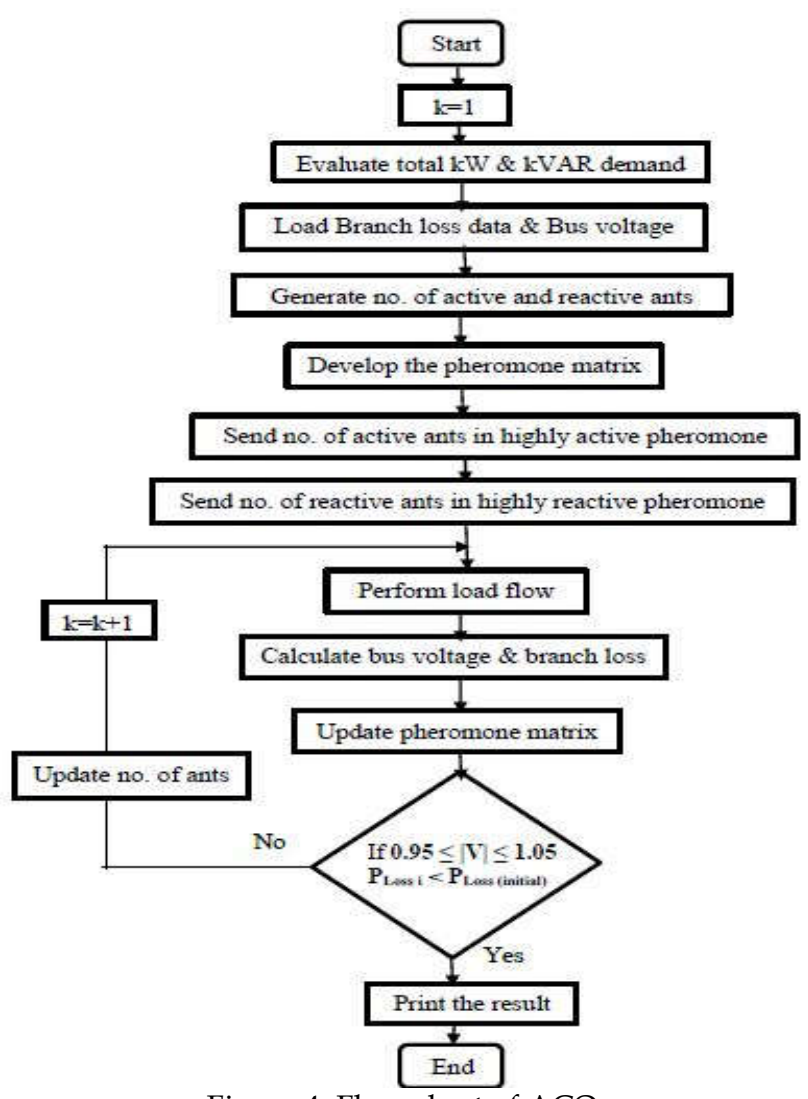

Figure 4: Flow chart of ACO 


\section{Ant Colony Optimization}

In this study, the ACO technique is used to choose the best location for DG penetration. In this method, the probability of most likely bus for DG penetration is identified by Equation 10, and the value of pheromone $\tau_{i j}$ will be updated as per every movement of an ant with Equation 11.

$$
P_{i j}(t)^{k}=\frac{\tau_{i j}^{\alpha} \times \eta_{i j}{ }^{\beta}}{\sum \tau_{i j}{ }^{\alpha} \times \eta_{i j}{ }^{\beta}} \text { ifjek;0 otherwise }
$$

Where, $P_{i j}(t)^{k}=$ Probability of choosing branch ij by an ant $\mathrm{k}$ at $\mathrm{i}^{\text {th }}$ iteration.

$\tau_{i j}=\frac{1}{\text { Branch loss } i j}, \alpha=$ control parameter for $\tau_{i j}, \eta_{i j}=1 /$ (busvoltage $(V j), \beta=$ control parameter for $\eta_{i j}$.

$$
\tau_{i j}(\mathrm{t}+\mathrm{n})=(1-\rho) \cdot \tau_{i j}(\mathrm{t})+\Delta \tau_{i j}
$$

Where, $1-\rho=$ pheromone evaporation rate, where the value of $\rho$ is considered to be 0.5 (Drigo, 1996).

In this way, active pheromone and reactive pheromone was evaluated with the help of active and reactive branch loss across corresponding bus voltage. Then the number of active and reactive ants will choose the highest pheromone path accordingly. As the main purpose is to integrate capacitor bank and solar PV on the distribution system for voltage profile improvement with minimization of branch loss; a number of active and reactive ants were generated. These ants have been following the highest pheromone path developed by the equation (10) \& (11) in continuous iteration unless the objective is reached in the optimum solution. In this analysis, assumptions made for the size of the active and reactive ants are $50 \mathrm{~kW}$ and $100 \mathrm{kVAR}$ respectively. Furthermore, the number of active and reactive ants were generated by Equation 12 and 13. Considering various technical aspects, the maximum permissible size of solar PV as a DG source is limited to $45 \%$ of the total connected load (Kadir et al., 2014). The proposed flowchart for ACO is shown in Figure 4.

$$
\begin{aligned}
& \text { No of Active ants }=\frac{\text { Total kw demand } * 0.45}{\text { Size of active ant (i. e. } 50 \mathrm{kw})} \\
& \text { No of Reactive ants }=\frac{\text { Total kvar demand }+ \text { kvar branch loss }}{\text { Size of reactive ant (i. e. } 100 \text { kvar) }}
\end{aligned}
$$

\section{Results and Discussion}

In this study, the spacing between the tapping points for transformers is considered as a bus, and the kVA rating of the transformer with $0.8 \mathrm{PF}$ is taken as a connected load with that bus. Distance between the two transformers is considered as the branch. Firstly, the proposed algorithm is tested on IEEE 33 bus system for validation and then used for the case study area. With the proposed methodology and assumptions, the following outcomes have been obtained:

\section{A. IEEE 33 Bus System}

Based on the pheromone value deposited on the branch, the ACO algorithm sends an arbitrary number of active and reactive ants to corresponding buses and performs the load flow analysis. The maximum number of active and reactive ants were generated by using equation (10) and (11) are 33 and 25. Once these ants follow the path concerning the pheromone deposited on the branch, the voltage profile of the system was found to be improved significantly with reduced branch loss for IEEE 33 bus system as shown in Figure 5 and 6. Total insertion of 2,500 kVAR capacitor bank and the $1500 \mathrm{kVA}$ of solar PV inverter capacity as shown in Table 3, reduced the branch losses significantly up to $82.3 \%$ as shown in Figure 6. It is clearly seen that the proposed method contributed to improving the voltage profile significantly, as well as the energy losses. Proposed ACO is used to identify the optimal location for the integration of DGs so that the system performance will be improved optimally. Table 3 gives the location of the bus and the integrated DGs, which were found to be optimal by using ACO. 


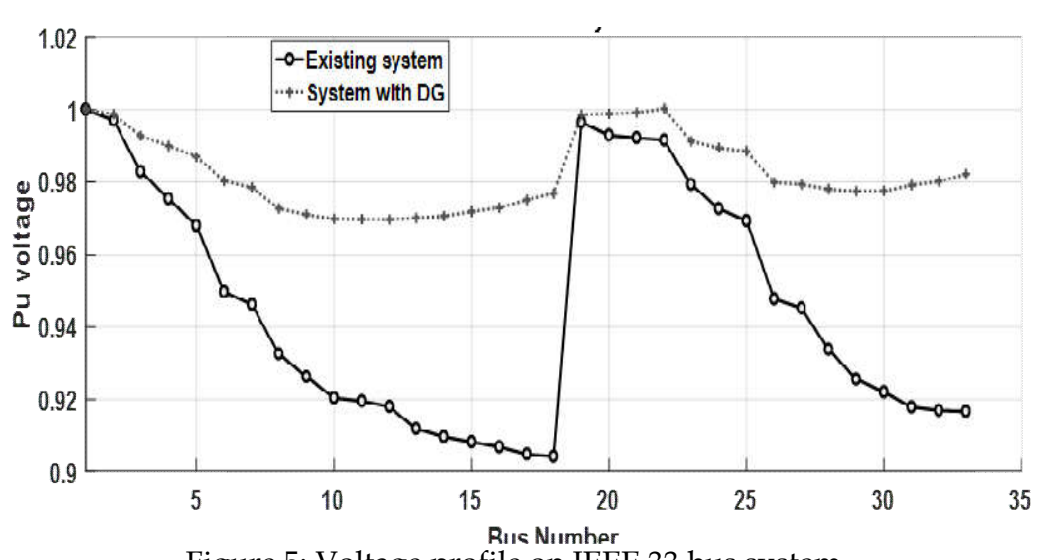

Figure 5: Voltage profile on IEEE 33 bus system

Table 3: DG integration on IEEE 33 bus system

\begin{tabular}{cccc}
\hline S.N. & Bus No. & Capacitor (kVAR) & PV inverter (kVA) \\
\hline 1 & 31 & 300 & 600 \\
2 & 21 & - & 400 \\
3 & 18 & - & 500 \\
4 & 30 & 500 & - \\
5 & 25 & 500 & - \\
6 & 24 & 400 & - \\
7 & 4 & 200 & $\mathbf{1 5 0 0}$ \\
\hline
\end{tabular}

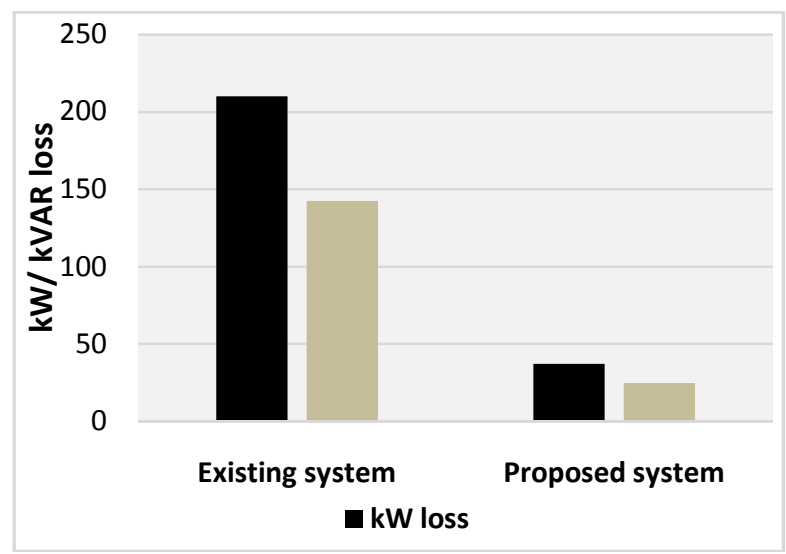

Figure 6: Branch loss of IEEE 33 bus system

\section{B. Case study of Laukhi Feeder}

Load flow of the actual system as shown in Figure 2 gives information about the system regarding voltage and branch loss. Based on that, the pheromone trail is developed and the suitable size and location of the DG and capacitor bank were identified. During the analysis, the base kV and base MVA of the system were considered to be $11 \mathrm{kV}$ and 100 MVA respectively. Load flow data of the existing system was converged in the seventh iteration using FBSA. Using $\mathrm{ACO}$, the following configurations are identified to improve the voltage and branch loss of the system as shown in Table 4.

In the base case (Existing system), the minimum voltage is encountered at bus number 21 with 0.83 pu, beyond the acceptable limit, i.e. $0.95 \mathrm{pu}$. To improve this voltage profile, we have an option to penetrate either solar PV or capacitor bank or both. With the integration of the capacitor bank only, a minimum voltage was found at bus number 43 with $0.966 \mathrm{pu}$. While with the insertion of both capacitor bank and solar PV, as presented in Table 4, the voltage profile of the system was significantly better than with the capacitor bank alone. In this arrangement, the minimum voltage was found at many buses with $0.989 \mathrm{pu}$. After integrating 2,500 kVAR of the capacitor bank and 1,600 kWp of a solar PV system, the impact on voltage and branch loss of the system is as shown in Figure 7. 


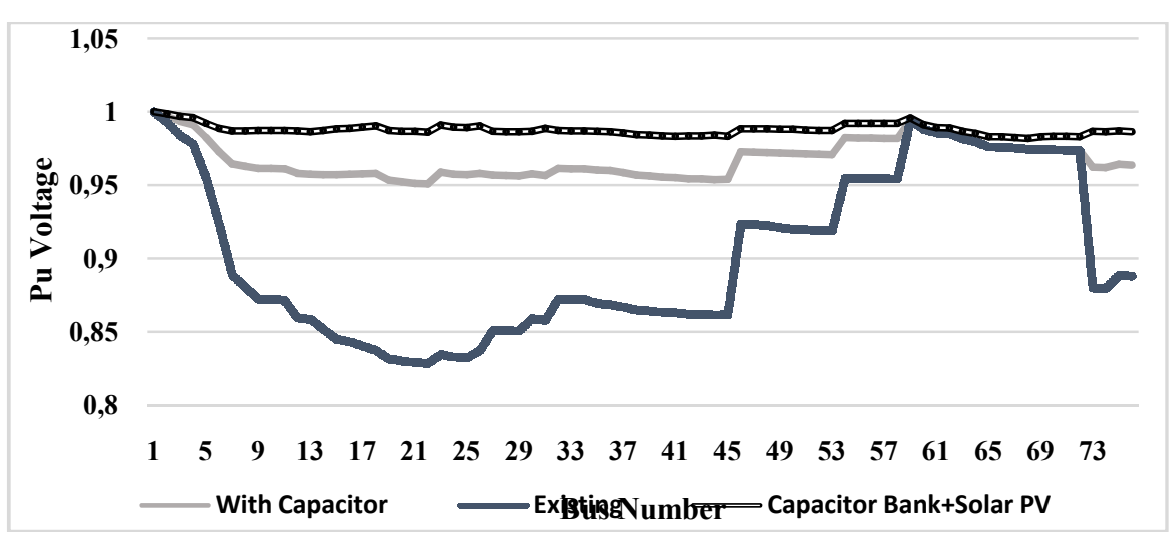

Figure 7: Voltage profile of the Laukahi feeder at different cases

Table 4: Location and Size of DG in Laukahi feeder

\begin{tabular}{cccc}
\hline S.N. & Bus No. & Capacitor (kVAR) & PV inverter (kVA) \\
\hline 1 & 31 & - & 300 \\
2 & 21 & - & 200 \\
3 & 70 & - & 300 \\
4 & 58 & - & 200 \\
5 & 18 & - & 200 \\
6 & 9 & - & 100 \\
7 & 44 & - & 200 \\
8 & 50 & 700 & 100 \\
9 & 10 & 600 & - \\
10 & 23 & 400 & - \\
12 & 36 & 500 & - \\
14 & 18 & 300 & $\mathbf{1 6 0 0}$ \\
\hline
\end{tabular}

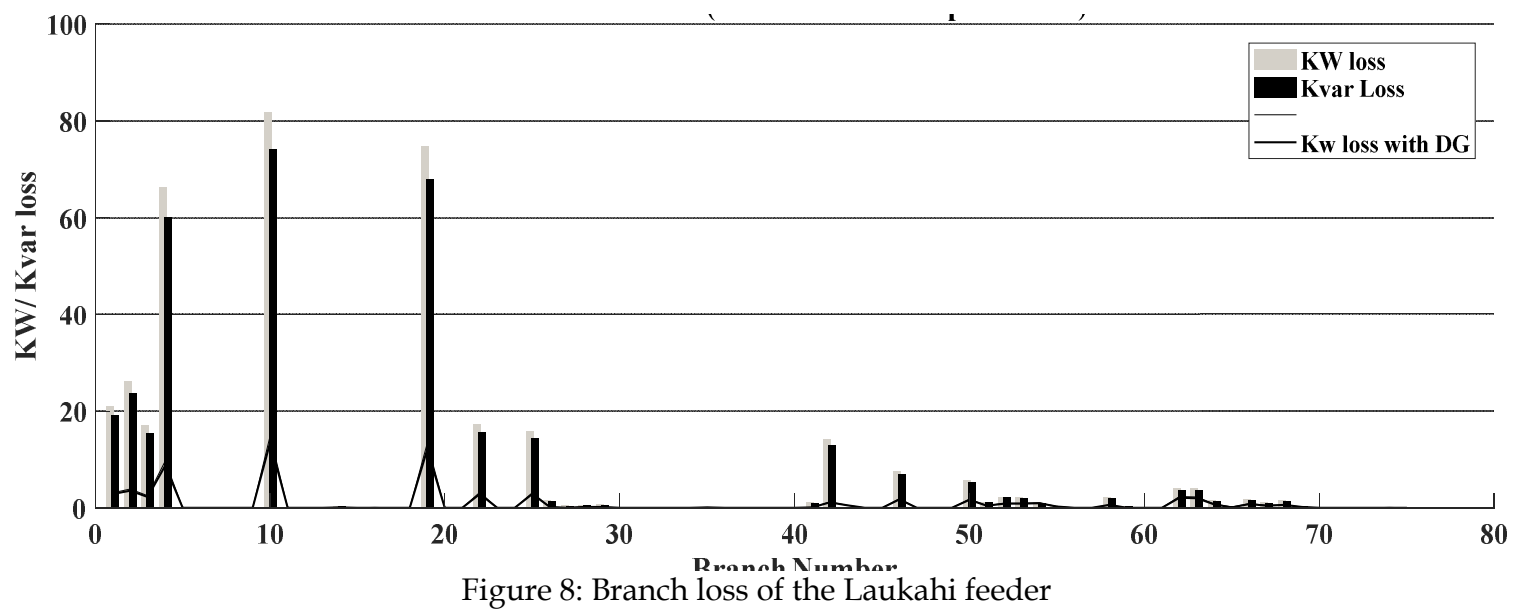

Similarly, it is identified that branch number 10 has the highest branch loss (kW and kVAR) comparing to other branches of the Laukahi feeder. Likewise, starting buses (4 to 7) has significant branch losses as shown in Figure 8. On the other hand, the impacts of DG insertion are also present in the total branch loss of the system. In the first case, considering the existing system, total losses are $379.23 \mathrm{~kW}$ and $344.55 \mathrm{kVAR}$ respectively. In the second case, with capacitor bank, branch losses have been reduced to $187.32 \mathrm{~kW}$ and $170.19 \mathrm{kVAR}$. Finally, in the third case, with the presence of both solar PV and capacitor bank, branch loss is further reduced to $48.48 \mathrm{~kW}$ and $44.047 \mathrm{kVAR}$. The existing system has a minimum voltage of $0.828 \mathrm{pu}$, which will be upgraded to $0.965 \mathrm{pu}$ with the proposed capacitor bank placement, and the branch loss will be reduced up to $50.6 \%$. If we used both the capacitor segment and the solar PV considered as mixed DG, significant improvement on the system can be observed as shown in Figure 9. Moreover, mixed DG reduced the system branch loss up to $87.22 \%$ considering the technical limitations of DG, the minimum voltage of the system is obtained $0.982 \mathrm{pu}$ at bus number 67 and the maximum voltage deviation is -4.050 at bus number 24 . 


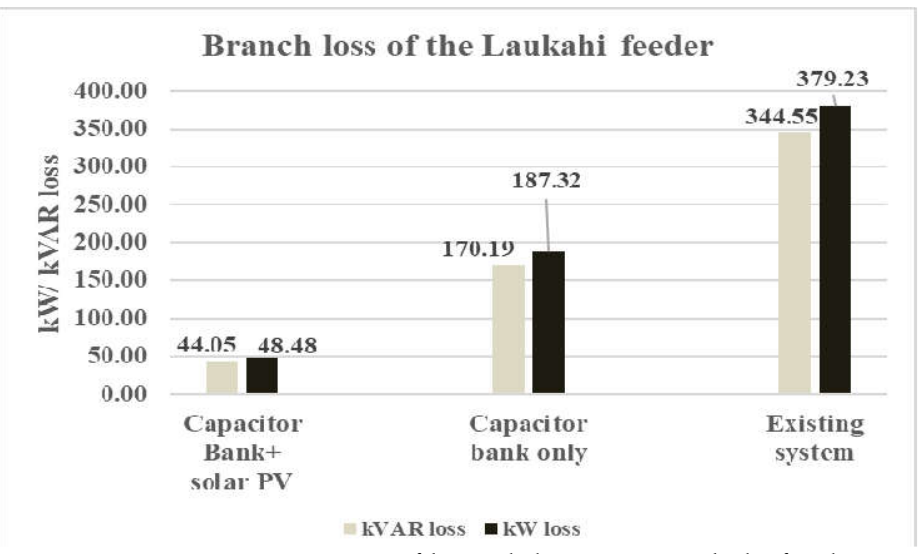

Figure 9: Comparison of branch losses in Laukahi feeder

\section{Conclusions}

Most of the distribution system in Nepal is radial. Due to the far-end active and reactive loads, the voltage profile of the system is being poor. In addition, a significant amount of branch loss is being encountered in the line. To overcome such a situation, simply DG penetration was not considered as the proper solution, rather appropriate size and location of DG insertion played a significant role in the system improvement. In this study, ant colony optimization is used to analyze the system that may help to improve the voltage profile and minimization of branch loss in the radial distribution system. Hence, for the specific case study area, the following conclusions have been drawn:

a. Branch loss of the Laukahi feeder can be reduced up to $87.22 \%$ using capacitor bank and solar PV.

b. The minimum system voltage of the Laukahi feeder can be upgraded from $0.8286 \mathrm{pu}$ to $0.982 \mathrm{pu}$.

c. A suitable place of DG penetration can be efficiently identified by using ant colony optimization technique.

d. A hybrid model combining different approaches can analyze the system's performance, and help in system planning and monitoring tasks.

\section{References}

Ackermann, T., Andersson, G., \& Söder, L. (2001). Distributed generation: a definition. Electric power systems research, 57(3), 195-204.

Balamurugan, P., Yuvaraj, T., \& Muthukannan, P. (2018). Optimal Allocation of DSTATCOM in Distribution Network Using Whale Optimization Algorithm. Engineering, Technology \& Applied Science Research, 8(5), 3445-3449.

Bompard, E., Carpaneto, E., Chicco, G., \& Napoli, R. (2000). Convergence of the backward/forward sweep method for the load-flow analysis of radial distribution systems. International journal of electrical power $\mathcal{E}$ energy systems, 22(7), 521-530.

Civanlar, S., Grainger, J., Yin, H., \& Lee, S. (1988). Distribution feeder reconfiguration for loss reduction. IEEE Transactions on Power Delivery, 3(3), 1217-1223.

Drigo, M. (1996). The ant system: optimization by a colony of cooperating agents. IEEE Transactions on Systems, Man, and Cybernetics-Part B, 26(1), 1-13.

Farhat, I. (2013). Ant colony optimization for optimal distributed generation in distribution systems. Paper presented at the Proceedings of World Academy of Science, Engineering and Technology.

Kadir, A., Fazliana, A., Khatib, T., \& Elmenreich, W. (2014). Integrating photovoltaic systems in power system: power quality impacts and optimal planning challenges. International Journal of Photoenergy, 2014.

Nikoukar, J., \& Gandomkar, M. (2005). Capacitor placement in distribution networks using ant colony algorithm. WSEAS Transactions on Systems, 4(1), 38-42.

Pazhaniraja, N., Paul, P. V., Roja, G., Shanmugapriya, K., \& Sonali, B. (2017). A study on recent bio-inspired optimization algorithms. Paper presented at the 2017 Fourth International Conference on Signal Processing, Communication and Networking (ICSCN).

Peng, S., Hong, H., Wang, Y., Wang, Z., \& Jin, H. (2014). Off-design thermodynamic performances on typical days of a 330 MW solar aided coal-fired power plant in China. Applied Energy, 130, 500-509.

Prenc, R., Škrlec, D., \& Komen, V. (2013). A novel load flow algorithm for radial distribution networks with dispersed generation. Technical Gazette, 20(6), 969-977.

Sah, S., Shrestha, A., \& Papadakis, A. (2018). Cost-Effective and Reliable Energy System for Kathmandu University Complex. Paper presented at the 11th International Conference on Deregulated Engineering Market Issues in South Eastern Europe, Nicosia, Cyprus.

Sahoo, S. K. (2016). Renewable and sustainable energy reviews solar photovoltaic energy progress in India: A review. Renewable and Sustainable Energy Reviews, 59, 927-939.

Sampath, E. P. A. (2015). VOLTAGE PROFILE IMPROVEMENT IN MV DISTRIBUTION LINE: COST OPTIMAL ALLOCATION OF REACTIVE POWER COMPENSATORS.

Seidlová, R., \& Poživil, J. (2005). Implementation of Ant Colony Algorithms in Matlab. Institute of Chemical Technology, 
Department of Computing and Control Engineering.

Shekhawat, A., Poddar, P., \& Boswal, D. (2009). Ant colony optimization Algorithms: Introduction and beyond. Department of Computer Science and Engineering: Indian Institute of Tecnology Bombay.

Shrestha, A. (2017). Planning, Design And Optimization Of Distribution System For Affected Area Of Upper Karnali Hydropower Project. (Masters' Degree in Planning and Operation of Energy Systems), Kathmandu University, Nepal.

Shrestha, A., Bickram Rana, L., Singh, A., Phuyal, S., Ghimire, A., Giri, R., . . Kumar Jha, S. (2019). Electricity Excess in an Isolated Hybrid System: A Case Study in Dangibada Village, Jumla, Nepal. Energy Procedia, 160(C), 76-83.

Shrestha, A., Bikram Shah, B., Raj Gautam, B., \& Kumar Jha, S. (2016). Framework Development to Analyze the Distribution System for Upper Karnali Hydropower Affected Area. International Journal of Modern Engineering Research, 7(4), 82-91.

Shrestha, A., Bikram Shah, B., Raj Gautam, B., Kumar Jha, S., \& Wagle, A. (2018). Load Flow Analysis of Primary Distribution System using Power System Analysis Tool (PSAT): A Case of Upper Karnali Hydropower Project. Paper presented at the 5th International Conference on Developments in Renewable Energy Technology, Kathmandu, Nepal.

Shrestha, A., Singh, A., Khanal, K., \& Maskey, R. (2016). Potentiality of off-grid hybrid systems for sustainable power supply at Kathmandu University campus. Paper presented at the Power Systems (ICPS), 2016 IEEE 6th International Conference on.

Shrestha, P., Shrestha, A., \& Adhikary, B. (2018). Comparative Analysis of Grid Integration on Distributed Energy System. Paper presented at the 5th International Conference on Developments in Renewable Energy Technology, Kathmandu, Nepal.

Singh, A., Shrestha, A., Phuyal, S., Adhikari, B., \& Papadakis, A. (2018). Particle Swarm Optimization Approach for Distributed Generation Allocation Planning for Voltage Profile Improvement. Paper presented at the 11th International Conference on Deregulated Engineering Market Issues in South Eastern Europe, Nicosia, Cyprus.

Teng, J.-H. (2003). A direct approach for distribution system load flow solutions. IEEE Transactions on Power Delivery, $18(3), 882-887$.

Verayiah, R., Mohamed, A., Shareef, H., \& Abidin, I. Z. (2014). Review of under-voltage load shedding schemes in power system operation. Przeglad Elektrotechniczny, 90(7), 99-103.

Yang, X.-S. (2009). Firefly algorithms for multimodal optimization. Paper presented at the International symposium on stochastic algorithms.

Yang, X.-S., \& Deb, S. (2009). Cuckoo search via Lévy flights. Paper presented at the 2009 World Congress on Nature \& Biologically Inspired Computing (NaBIC).

Yazdani, M., \& Jolai, F. (2016). Lion optimization algorithm (LOA): a nature-inspired metaheuristic algorithm. Journal of computational design and engineering, 3(1), 24-36. 